\title{
La comunicación sobre la pandemia del COVID-19 en la era digital: manipulación informativa, fake news y redes sociales
}

\section{Communication on the COVID-19 pandemic in the digital age: disinformation, fake news and social media}

$\square$ $n$ el fragor de la pandemia del coronavirus que estamos atravesando actualmente, los epidemiólogos nos recuerdan que se trata de un acontecimiento que muchos ya habían anunciado que iba a suceder en cualquier momento y que sus numerosas advertencias no fueron tomadas en serio (Murdoch, 2020). Mientras que el foco actual se encuentra en cómo salir de esta crisis sanitaria, política y social sin precedentes, es necesario centrarnos en analizar qué está pasando y repensar nuevas estrategias para fortalecer los sistemas de respuesta tanto a nivel nacional como internacional, y así evitar que una nueva transmisión vírica al ser humano, o una mutación de alguno ya conocido, pueda volver a provocar una crisis de esta índole. En esta tarea, la comunicación se posiciona como un elemento esencial y prioritario en la gestión de cualquier crisis de salud pública.

Como se anunciaba en un artículo publicado en MIT Technology Review el 12 de febrero de 2020, la COVID-19 es la primera pandemia global de las redes sociales (Hao \& Basu, 2020), hecho que ha provocado numerosos desafíos con relación a la comunicación. El más notorio ha sido la elevada difusión de información falsa y fake news a través de medios digitales como redes sociales, páginas web y canales de mensajería instantánea como Whatsapp (Elías \& Catalan-Matamoros, 2020). Cualquier persona con educación escolar básica y en su sano juicio podría reírse de la extraña idea de que un virus biológico se propaga a través de las redes de telefonía móvil, o que la radiación de tales redes suprime el sistema inmunitario contra el virus. Sin embargo, a medida que el coronavirus causaba estragos en todo el mundo, estas dos afirmaciones han sido capaces de convencer a muchas personas para que salgan a la calle y prendan fuego cientos de mástiles telefónicos $5 G$ en muchos países, desde Australia y Nueva Zelanda hasta el Reino Unido, Irlanda, Finlandia, Suecia, Bélgica, los Países Bajos e Italia (Cerulus, 2020; Lewis, 2020). Pero estos son únicamente dos ejemplos de toda la información falsa que ha circulado por los medios digitales durante la pandemia que, además, ha sido tristemente compartida por algunos políticos, famosos, influencers, provocando que este tipo de información se difundiera mucho más rápido que el propio virus. De hecho, a mediados de febrero 2020, la Organización Mundial de la Salud declaró la situación de infodemia para alertar a los países de la escalada de información falsa que también se tenía que combatir junto a la expansión del virus.

Los gigantes de los medios sociales, Facebook, Twitter, YouTube y Whatsapp han reforzado sus filtros de fact-checking para reducir la información falsa en sus plataformas, incluyendo la retirada de fake news, aunque un estudio ha encontrado que una alta proporción de estos contenidos sigue visible en las plataformas (Brennen et al., 2020). También han establecido una estrecha colaboración con la Organización Mundial de la Salud y autoridades sanitarias nacionales para garantizar la publicación de información veraz sobre el virus y que ésta pueda ser accesible desde sus plataformas. Por ejemplo, Facebook ha creado el Centro de Información sobre el Coronavirus (Facebook, 2020a) en el que publican información actualizada y segura sobre el avance de la pandemia. Además, la app de Facebook muestra en la parte superior de la cuenta del usuario una sección con noticias, información y recomendaciones relativas al coronavirus, y también han publicado una web con recursos de información para los periodistas y otros profesionales de los medios de comunicación, así como una guía con cinco recomendaciones (Facebook, 2020b).

Estas iniciativas constituyen un frente de ataque a la información falsa, pero ¿es suficiente? Estas intervenciones técnicas pueden mitigar la crisis actual, sin embargo debemos irnos años atrás para observar como la infodemia actual no es algo reciente. Muchas de las teorías conspiratorias sobre la COVID-19 no son nuevas, han sido renovadas de otras ya elaboradas en el pasado. El ataque conspiratorio al $5 \mathrm{G}$ ha sido promovido por el movimiento activista anti-5G liderados por los grupos Stop $5 G$ que hay alrededor del mundo. Otras teorías conspiratorias que han sido usadas también en el pasado argumentan que el coronavirus es un producto de la codicia de las grandes empresas farmacéuticas, 0 
que la élite global está intentando controlar el crecimiento de la población. Estas son historias ya contadas por los movimientos anti-vacunas en las últimas décadas. A pesar de que estos argumentos han recibido un contundente rechazo en numerosas ocasiones por la comunidad científica y las autoridades sanitarias, contenidos similares siguen apareciendo como en el SARS (2002-2004), H1N1 (2009-2010), MERS (20122013), Ébola (2014-2015) y Zika (2015-2016). Lo que ahora estamos presenciando en la información sobre el coronavirus, según parece, es el nivel más avanzado de este proceso de creación y difusión masiva de historias falsas que, además, alienta la existencia de muchos otros movimientos pseudocientíficos tales como la negación del cambio climático, el creacionismo, antivacunas, la teoría de la tierra plana, etc. Sin embargo, el origen del problema es más complejo de lo que parece ya que las redes sociales únicamente han dado visibilidad a este tipo de información (Nguyen \& Catalan-Matamoros, 2020). Muchas personas presentan un deseo de creer en cosas que, según estándares intelectuales normales, son inequívocamente contrarios al pensamiento científico. Este es un problema de base social, cultural y política con una trayectoria más longeva que Internet. Corresponde a una variedad de factores que pueden fácilmente influir en el razonamiento humano siguiendo hábilmente intereses de origen político, económico, religioso, etc. Algunos de estos factores son los valores y creencias propias de la persona, pobre alfabetismo en salud y ciencia, crisis de las vocaciones STEM, uso inadecuado de medios digitales, baja inteligencia emocional, y/o poca habilidad para comprender varios puntos de vista sobre un hecho (Coleman, 2018; Rowe \& Alexander, 2017). Por ejemplo, las creencias previas pueden dificultar que las personas modifiquen sus percepciones falsas (Kuklinski et al., 2000; Nyhan \& Reifler, 2015). Un estudio incluso muestra que los intentos explícitos dirigidos a corregir falsas creencias con datos y hechos científicos pueden ser contraproducentes, llevando a las personas a respaldar más firmemente sus creencias previas (Betsch et al., 2013). En otras palabras, los medios digitales actúan más como un transmisor de desinformación en un entorno donde el conocimiento científico basado en hechos y evidencia no siempre son considerados por el público como la única verdad.

Por todo lo anterior, la lucha contra la información falsa y las fake news sobre salud y la ciencia en general debe comenzar por reconocer que los datos científicos, la verificación de datos y la corrección de la información no es suficiente para combatir la infodemia actual. Para ello se debe analizar el contexto socio-cultural en el que vivimos, gobernado por el declive de expertos y especialistas, el aumento de políticos populistas sin perfil científico, y de manera más profunda, la psicología social de las emociones, valores y creencias (Nguyen \& CatalanMatamoros, 2020). Para paliar la actual infodemia del coronavirus, es necesario elaborar estrategias de comunicación que respondan a las necesidades de las audiencias, así como tener en cuenta que los seres humanos no siempre seguimos un razonamiento lógico y racional (George \& Selzer, 2007). Para ello, sería necesario un conocimiento profundo sobre cómo las redes sociales facilitan o limitan la interacción entre datos científicos con emociones, valores y creencias, así como su influencia sobre la percepción pública sobre salud y ciencia en general.

El número especial 'La comunicación ante la pandemia de la COVID-19'

Como la comunicación juega un papel esencial en brotes, epidemias, crisis sanitarias y otros tipos de eventos de salud pública, y con el objetivo de reflejar el momento trascendental en el que nos encontramos, desde la Revista Española de Comunicación en Salud hemos considerado crucial publicar un número especial sobre la comunicación de la pandemia de la COVID-19 para aportar diversos análisis y facilitar una mejor comunicación en futuras crisis que, sin lugar a dudas, vamos a seguir teniendo.

Este número especial ofrece una perspectiva académica e investigadora de las rutinas y flujos de información durante esta pandemia, la selección y uso de fuentes de información, aspectos éticos y deontológicos, el rol de Internet y redes sociales, entre otros ámbitos. Para ello, hemos contado con una recepción de artículos sorprendentemente numerosa demostrando que la comunidad científica, muy sensible a la situación que la sociedad está atravesando, está centrando sus esfuerzos hacia la COVID-19 para comprender qué ha sucedido, qué está pasando y cómo podemos mejorar la comunicación en futuras crisis de salud pública. El número especial está formado por un total de 30 artículos que han sido seleccionados y han superado el proceso de revisión incluyendo artículos originales, originales breves, 
perspectivas y cartas al editor. Estos artículos traen un conjunto de datos nuevos con base empírica y teórica aportando un corpus científico sobre la comunicación durante la pandemia del coronavirus.

Los artículos originales y originales breves se centran en la gestión de la comunicación de los influencers farmacéuticos españoles, la evolución y viralización de informaciones falsas, los aspectos éticos de la cobertura fotográfica, la influencia de la comunicación en la coordinación de la atención geriátrica, la polarización y confianza en los medios españoles, las enseñanzas de los thrillers epidémicos, las plataformas fact-checking, la actuación en redes sociales de las autoridades sanitarias, las conferencias de prensa, el rol de la prensa así como el análisis de sus portadas y contenidos, la representación gráfica, el auge de la red social TikTok durante la pandemia, las cartas solidarias, y los contenidos en páginas web de organizaciones sanitarias.

Los artículos de perspectiva y las cartas al editor pretenden ofrecer una reflexión más personal sobre el estado de la cuestión realizadas por investigadores/as y académicos/as. Los artículos se dirigen hacia las fake news, el rol de la radio, tipos de relatos informativos, comunicación institucional y actividad informativa del gobierno y autoridades sanitarias, la incertidumbre en la presentación de datos, así como el renacimiento mediático de la cloroquina.

En conjunto, este número especial arroja datos nuevos y relevantes sobre aspectos brillantes y oscuros de la comunicación durante la pandemia del coronavirus, y ofrece ideas útiles tanto para mitigar sus aspectos negativos como para fomentar sus aspectos positivos. En nombre del Comité Editorial de RECS queremos agradecer a todos los autores y autoras su contribución en este número especial, teniendo en cuenta la difícil situación personal y profesional en la que muchos se pueden encontrar. Esperamos que los contenidos estimulen muchas preguntas para futuras investigaciones en un área cada vez más crucial que no solo salvaguarde la ciencia y mejore las humanidades, sino que en última instancia también pueda salvar vidas.

\section{Referencias bibliográficas}

Betsch, C., Renkewitz, F., \& Haase, N. (2013). Effect of Narrative Reports about Vaccine Adverse Events and Bias-Awareness Disclaimers on Vaccine Decisions: A Simulation of an Online Patient Social Network. Medical Decision Making, 33(1), 14-25. https://doi. org/10.1177/0272989X12452342

Brennen, J. S., Simon, F., Howard, P., \& Nielsen, R. K. (2020, abril 7). Types, sources and claims of Covid-19 misinformation. Reuters Institute. Recuperado de https://reutersinstitute.politics.ox.ac.uk/types-sourcesand-claims-covid-19-misinformation

Cerulus, L. (2020, abril 29). How anti-5G anger sparked a wave of arson attacks. Politico. Recuperado de https://www.politico.eu/article/coronavirus-5g-arsonattacks-online-theories/

Coleman, M. C. (2018). The Role of Patience in Arguments About Vaccine Science. Western Journal of Communication, 82(4), 513-528. https://doi.org/10 .1080/10570314.2017.1294708

Elías, C., \& Catalan-Matamoros, D. (2020). Coronavirus in Spain: Fear of 'Official' Fake News Boosts WhatsApp and Alternative Sources. Media and Communication, 8(2), 462. https://doi.org/10.17645/mac.v8i2.3217

Facebook. (2020a). Coronavirus (COVID-19) Information Centre. Facebook. Recuperado de https://www.facebook.com/coronavirus_info/

Facebook. (2020b). Coronavirus (COVID-19) Information Hub for Media. Facebook. https://www. facebook.com/facebookmedia/solutions/coronavirusresources

George, A., \& Selzer, J. (2007). Kenneth Burke in the 1930s. University of South Carolina Press.

Hao, K., \&Basu, T. (2020, febrero 12). The coronavirus is the first true social-media "infodemic". Recuperado de https://www.technologyreview.com/2020/02/12/844851/ the-coronavirus-is-the-first-true-social-media-infodemic/

Kuklinski, J. H., Quirk, P. J., Jerit, J., Schwieder, D., \& Rich, R. F. (2000). Misinformation and the Currency of Democratic Citizenship. The Journal of Politics, 62(3), 790-816. https://doi.org/10.1111/0022-3816.00033 
Lewis, K. (2020, marzo 26). $5 \mathrm{G}$ is not accelerating the spread of the new coronavirus. Recuperado dehttps:// fullfact.org/health/5G-not-accelerating-coronavirus/

Murdoch, D. (2020, junio 14). The next once-a-century pandemic is coming sooner than you think - but COVID-19 can help us get ready. The Conversation. Recuperado de https://theconversation.com/the-nextonce-a-century-pandemic-is-coming-sooner-than-youthink-but-covid-19-can-help-us-get-ready-139976

Nguyen, A., \& Catalan-Matamoros, D. (2020). Digital Mis/ Disinformation and Public Engagment with Health and Science Controversies: Fresh Perspectives from Covid-19. Media and Communication, 8(2), 323. https://doi.org/10.17645/mac.v8i2.3352

Nyhan, B., \& Reifler, J. (2015). Does correcting myths about the flu vaccine work? An experimental evaluation of the effects of corrective information. Vaccine, 33(3), 459-464. https://doi.org/10.1016/j. vaccine.2014.11.017

Rowe, S., \& Alexander, N. (2017). Food and Nutrition Science Communications: Behind the Curtain. Nutrition Today, 52(4), 179-182. https://doi. org/10.1097/NT.0000000000000229

\section{Daniel Catalán-Matamoros}

Editor-Jefe RECS, Departamento de Comunicación, Universidad Carlos III de Madrid, España

అ dacatala@hum.uc3m.es 